
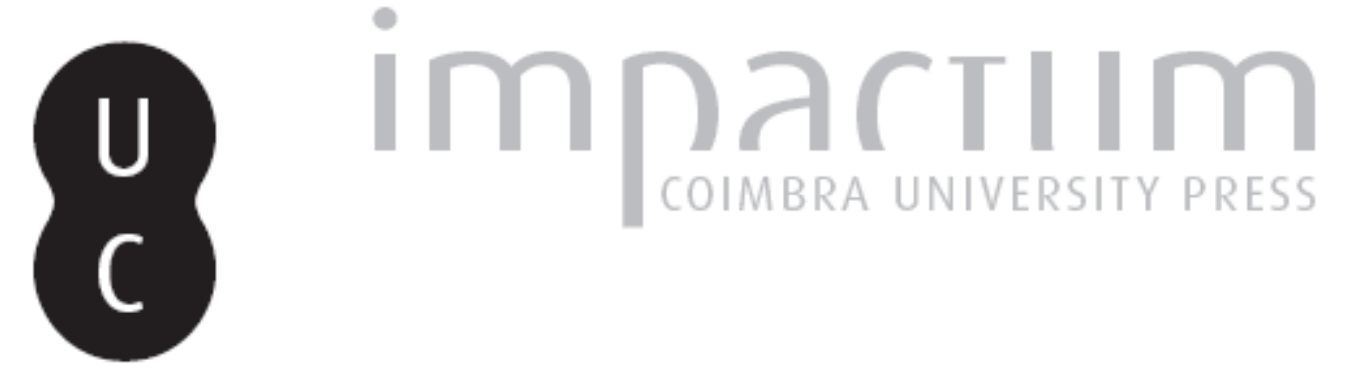

\title{
Hábito epigráfico romano en El Conventus Lucensis
}

Autor(es): $\quad$ Abascal Palazón, Juan Manuel

Publicado por: Faculdade de Letras da Universidade de Coimbra/Imprensa da Universidade de Coimbra

URL persistente:

URI:http://hdl.handle.net/10316.2/41874

DOI:

DOI:https://doi.org/10.14195/1647-8657_55_11

Accessed : $\quad$ 26-Apr-2023 15:28:11

A navegação consulta e descarregamento dos títulos inseridos nas Bibliotecas Digitais UC Digitalis, UC Pombalina e UC Impactum, pressupõem a aceitação plena e sem reservas dos Termos e Condições de Uso destas Bibliotecas Digitais, disponíveis em https://digitalis.uc.pt/pt-pt/termos.

Conforme exposto nos referidos Termos e Condições de Uso, o descarregamento de títulos de acesso restrito requer uma licença válida de autorização devendo o utilizador aceder ao(s) documento(s) a partir de um endereço de IP da instituição detentora da supramencionada licença.

Ao utilizador é apenas permitido o descarregamento para uso pessoal, pelo que o emprego do(s) título(s) descarregado(s) para outro fim, designadamente comercial, carece de autorização do respetivo autor ou editor da obra.

Na medida em que todas as obras da UC Digitalis se encontram protegidas pelo Código do Direito de Autor e Direitos Conexos e demais legislação aplicável, toda a cópia, parcial ou total, deste documento, nos casos em que é legalmente admitida, deverá conter ou fazer-se acompanhar por este aviso. 
CONIMBRIGA

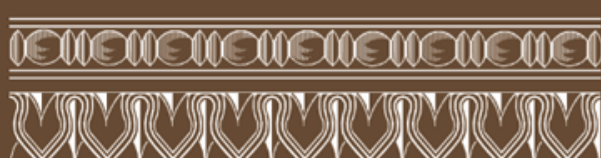

INSTITUTO DE ARQUEOLOGIA

VOLUME LV • 2016

FACULDADE DE LETRAS
UNIVERSIDADE DE COIMBRA 
Juan Manuel Abascal Palazón

Universidad de Alicante

juan.abascal@ua.es

\title{
HÁBITO EPIGRÁFICO ROMANO EN EL CONVENTUS LUCENSIS
}

\author{
THE EPIGRAPHIC ROMAN HABIT AT THE CONVENTUS LUCENSIS \\ “Conimbriga" LV (2016) p. 193-219 \\ https://doi.org/10.14195/1647-8657_55_11
}

RESUMEN: Las inscripciones del conventus Lucensis muestran un reparto geográfico muy desigual, con una importante concentración en la ciudad de Lucus Augusti y vacíos muy importantes en las comarcas nororientales y septentrionales; llama la atención también la escasez de testimonios en el espacio comprendido entre los ríos Eo y Navia. La mayor parte de las inscripciones están elaboradas en granito y el tipo más corriente es el altar votivo. No tenemos constancia de la existencia de officinae epigráficas pero los monumentos respetan estilos y modas conocidos en otras regiones. Esa ausencia de officinae probablemente fue causa de un alto grado de creatividad epigráfica, especialmente en lo relativo a las representaciones figuradas.

Palabras Clave: Inscripciones romanas, Gallaecia, Hispania, Lucus Augusti.

SUMARY: The inscriptions of the conventus Lucensis show a very irregular geographic distribution, with an important concentration in the city of Lucus Augusti and very significant gaps in the northeastearn and northern regions; the lack of testimonies in the space between the rivers Eo and Navia is also noteworthy. The biggest part of the inscriptions are made of granite and the most common type

Conimbriga, 55 (2016) 193-219 
is the votive altar. We don't have any record of the existence of epigraphic officinae but the monuments respect styles and trends known in other regions. This absence of officinae was probably the cause of a high degree of epigraphic creativity, especially regarding the figurative representations

KeYwords: Roman Inscriptions, Gallaecia, Hispania, Lucus Augusti. 


\section{HÁBITO EPIGRÁFICO ROMANO EN EL CONVENTUS LUCENSIS}

En la edición de 1869 del volumen II del Corpus Inscriptionum Latinarum (CIL II), Hübner ya percibió las dificultades para definir territorialmente el conventus Lucensis y para precisar las cuestiones relativas a su topografía. A los problemas derivados de la insuficiente cartografía existente en el siglo XIX, hubo de añadir la escasez de datos geográficos en las fuentes antiguas y las dificultades para entender la organización administrativa de un territorio en el que, por debajo del concello y de la parroquia, existían otras muchas entidades menores de población cuya ubicación exacta desconocía ${ }^{1}$. Eso explica la prolongada disertación hübneriana al comienzo del capítulo dedicado al conventus Lucensis, cuando comparó la situación con la que ya había encontrado en el conventus Bracaraugustanus e in totius Lusitaniae eius partis, quae a Tago et Ana fluviis septentrionem versus sita est (CIL II p. 351).

Como consecuencia de esas dificultades, Hübner optó por presentar el conjunto de inscripciones -obviamente sin incluir los miliariosagrupado en seis unidades que fueron las siguientes:

I Oppida vallis Minii fluvii (n. $\left.{ }^{\circ} 2526-2538\right)$

II Iria Flavia (n. $\left.{ }^{\circ} 2539-2550\right)$

III Castrum S. Christophori (n $\left.{ }^{\circ} 2551-2557\right)$

IV La Coruña (n. $\left.{ }^{\circ} 2558-2569\right)$

V Lucus Augusti (n. $\left.{ }^{\circ} 2570-2596\right)$

VI Loci Gallaeciae incerti (n. $\left.{ }^{\circ} 2597-2605\right)$

En el supplementum de 1892 se mantendría esta misma estructura

\footnotetext{
${ }^{1}$ Este trabajo se ha realizado en el marco del proyecto de investigación HAR201565168-P (MINECO/FEDER) de la Secretaría de Estado de Investigación, Desarrollo e Innovación del Gobierno de España.
}

Conimbriga, 55 (2016) 193-219 
y se añadirían los n. ${ }^{\circ}$ 5625-5648. Entre esos seis grupos se contaba el castrum Sancti Christophori, que ahora sabemos que fue la denominación con que se identificaron los textos procedentes de la localidad leonesa de Villalís y que, en consecuencia, no pueden vincularse al conventus Lucensis. Entre las piezas incluidas en los loci Gallaeciae incerti se encontraban inscripciones de Santa María de Zaparín (Cortegada, OR. CIL II 2597), Pobra de Trives (OR. CIL II 2601-2602, 2604-2605), Rosinos de Vidriales (ZA. CIL II 2600) y de procedencia desconocida (CIL II 2598-2599, 2603), todas ajenas al conventus.

A eso hay que añadir que bajo la denominación de oppida Vallis Minii fluvii se incluyeron las inscripciones de la ciudad de Orense, de Santa Comba de Bande y de otras localidades que hoy consideramos como parte del conventus Bracarum. Esta inclusión no era sino consecuencia de la falta de evidencias documentales para optar por otro criterio, pero supuso una definición territorial para el conventus $\mathrm{Lu}$ censis algo más extensa que la que hoy parece más probable en el más optimista de los supuestos.

Ni la Naturalis historia de Plinio ni el resto de las fuentes antiguas ${ }^{2}$ definen con precisión los límites del conventus Lucensis. Sabemos que el río Navia separaba este conventus del Asturum (Plin., Nh. 4, 34, 111) pero el límite meridional es menos preciso. En la descripción de norte a sur de la costa gallega, Plinio hace terminar el conventus Lucensis con los Cileni y añade que, después de éstos, comienza el conventus Bracarum con los Heleni, los Grovi, el castellum Tyde (Tui, Pontevedra), las insulae Siccae, el oppidum de Abobrica y el río Minius (Miño) (Plin., Nh. 4, 34, 112) . $^{3}$.

El texto pliniano parece descartar que el río Miño fuera un límite conventual, pese a que su importante caudal y su anchura en algunos tramos así lo haga suponer. Hay que recordar que tampoco el río Ebro o el Guadalquivir -salvo cerca de su desembocadura-fueron límites de conventos jurídicos (ABASCAL 2015a, 134).

La ubicación de este límite meridional ha dado pie a numerosas

${ }^{2}$ Las fuentes antiguas sobre los territorios de Gallaecia están recogidas en Romero - Pose 1988. Véase también Suárez Piñeiro 2002, 9-26. El estudio detenido de la toponimia de Gallaecia en época romana y el establecimiento del catálogo de topónimos es obra de Curchin 2008, 109-136.

${ }^{3}$ El análisis de todos los topónimos puede verse con detalle en Curchin 2008, passim.

Conimbriga, 55 (2016) 193-219 
conjeturas desde el siglo XVIII, algunas de ellas sin base documental alguna. Un trabajo de D. Estefanía Álvarez publicado en 1958 ya puso de manifiesto que el estudio de los miliarios podía ser una base de estudio bastante sólida, pues el cómputo de las millas parecía hacerse con respecto a diversas ciudades dentro de un mismo recorrido. Al aplicar esta medotología al límite entre los conventus Lucensis y Bracarum, Estefanía observó que, en una zona cercana a Pontevedra, algunos miliarios de la vía de Bracara Augusta a Asturica ${ }^{4}$ por Turoqua, comúnmente identificada como vía XIX ${ }^{5}$, expresaban el cómputo desde Bracara Augusta y otros desde Lucus Augusti, por lo que llegó a la conclusión de que el límite territorial debía encontrarse entre Redondela y Almuiña (Estefanía 1958, 54-55), es decir, en algún lugar cercano al fondo de la ría de Vigo. Su propuesta, aunque modificada ligeramente después, constituye la base de los puntos de vista más recientes (RoDRÍGUEZ COLMENERO 1972, 135-163; TRANOY 1981, 160-162), que han ido precisando ese dato a partir de la información proporcionada por los miliarios y de la fijación rigurosa de su lugar de hallazgo. En último término, un análisis meticuloso de los testimonios epigráficos de Vilaboa y Arcade (Pontevedra), así como la revisión de la topografía de los hallazgos y de los límites episcopales altomedievales, ha permitido a R. Álvarez Asorey proponer que, en la zona próxima a la costa, el límite conventual discurriera por el río Verdugo (Állvarez Asorey 2001, 175; RODRÍGUEZ COLMENERO et alii 2004, 225-226). Evidentemente, de esto no se puede colegir que este río tuviera una especial significación en la topografía de época romana, sino que ahí o en sus proximidades se encontraba el límite entre los Cileni del conventus Lucensis y los Heleni del conventus Bracarum ${ }^{6}$, de forma que la administración romana de época augustea aprovechó un antiguo límite étnico para delimitar estas dos circunscripciones conventuales?

${ }^{4}$ Sobre este trazado, véase en detalle RodríGUEz COLMENERo et alii 2004, 211 352 , con un minucioso análisis del recorrido, de las evidencias epigráficas y de la bibliografía anterior. A esa bibliografía, añádanse FrANCo 2001, 217-248 y SÁEZ TABOADA 2002, 389-408.

${ }^{5}$ It. Ant. 429, 5 - 431, 3.

${ }^{6}$ Según J. de Alarcão (1998, 53 y mapa; Id. 2003, 122 Fig. 1), los Heleni plinianos deberían encontrarse en la zona de Vigo y Tyde (Tui) sería el castellum de los Grovii.

${ }^{7}$ Los criterios étnicos fueron sólo algunos de los que pudo emplear Roma para adscribir los territorios a uno u otro conventus. Un examen detallado de la

Conimbriga, 55 (2016) 193-219 
Esta solución, que es la que hemos aceptado para la edición revisada del fascículo correspondiente al conventus Lucensis del Corpus Inscriptionum Latinarum, deja dentro de esta demarcación toda la península de Morrazo y el santuario del Lar Berobreus. Al oriente del río Verdugo, el límite conventual iría a encontrar el río $\mathrm{Bubal}^{8}$ y seguiría este cauce hasta su desembocadura en el Miño. A partir de allí, continuaría aguas arriba el curso del Sil hasta la desembocadura del Lor (FIG. 1). Desde aquí, el límite del conventus Lucensis giraría hacia el norte para seguir el curso del río hasta su nacimiento y buscar las fuentes del Navia (RodríGuez Colmenero et alii 2004, 372), que señala en todo su trazado la línea divisoria entre los conventus Lucensis y Asturum (Plin., Nh. 4, 34, 111), hasta su desembocadura en el Cantábrico.

Entre 1869 (CIL II) y 1899 (Ephemeris Epigraphica VIII), el número de inscripciones no miliarias descritas por Hübner en este territorio fue de 68. Hoy en día, si excluimos los miliarios y los grafitos cerámicos sin trascendencia onomástica, el ámbito territorial definido en la Fig. 1 incluye 545 epígrafes, contabilizando entre ellos los fragmentos decorados que no conservan texto pero que prueban la existencia de un monumento epigráfico antiguo. Como puede verse, el volumen epigráfico de la región ha crecido de forma significativa en poco más de un siglo. Un alto porcentaje de ese total, aproximadamente un $24 \%$, procede de la ciudad de Lucus Augusti y casi un 23\% está constituido por los altares del santuario del Monte do Facho de Donón (O Hío, Pontevedra $)^{9}$.

\begin{tabular}{|c|c|c|c|}
\hline & Granito & Otros / desconocido & Total \\
\hline n. $^{\circ}$ & 412 & 133 & 545 \\
\hline$\%$ & 75,60 & 24,40 & 100,00 \\
\hline
\end{tabular}

TABLA 1. Proporción de los soportes de granito en el conventus Lucensis.

cuestión puede verse en Ozcáriz 2013, 63-65, con la discusión del tema y la bibliografía anterior.

${ }^{8}$ Idea que agradezco a A. Rodríguez Colmenero.

${ }^{9}$ Fariña - Suárez 2002, 25-52; Koch 2005, 135-183; Schattner - Suárez - Koch 2004, 23-71; Eid. 2005, 135-183; Eid. 2006a, 169-192 (=2006b, 183-223); Eid. 2014, 249-268.

Conimbriga, 55 (2016) 193-219 
En terminos generales, la producción epigráfica del conventus Lucensis está protagonizada por los soportes de granito, que constituyen el 75,6\% de los testimonios conocidos (TABLA 1). Si se tiene en cuenta que las cifras que presentamos excluyen los miliarios, y que el apartado de "otros" incluye las inscripciones hoy perdidas y que pudieron ser de granito, debe entenderse que este tipo de roca fue empleado de forma dominante para la elaboración de inscripciones en este ámbito geográfico durante los primeros siglos del Principado.

\begin{tabular}{|c|c|c|c|c|c|}
\hline & Votivas & Funerarias & Grafitos & Otros / desconocido & Total \\
\hline n. $^{\text {o }}$ & 286 & 143 & 42 & 74 & 545 \\
\hline$\%$ & 52,48 & 26,24 & 7,71 & 13,58 & 100,00 \\
\hline
\end{tabular}

TABLA 2 - Tipos de inscripciones en el conventus Lucensis.

\begin{tabular}{|c|c|c|c|c|c|}
\hline & Votivas & Funerarias & Grafitos & Otros / desconocido & Total \\
\hline n. ${ }^{\circ}$ & 158 & 143 & 42 & 74 & 417 \\
\hline$\%$ & 37,89 & 34,29 & 10,07 & 17,75 & 100,00 \\
\hline
\end{tabular}

TABLA 3 - Tipos de inscripciones en el conventus Lucensis, excluidos los testimonios del Facho de Donón.

Un segundo dato relevante es el referido a los textos de los monumentos. Más de la mitad de los identificados, un 52,48\%, son textos votivos (TABLA 2), mientras que el número de inscripciones funerarias se reduce casi a la cuarta parte del total $(26,24 \%)$. Estas cifras no guardan ninguna relación con las proporciones medias del Imperio Romano, en donde los textos funerarios son claramente mayoritarios (ABASCAL 2003, 265). De hecho, en 1982, G. C. Susini estimó en unas 300.000 las inscripciones romanas existentes en el mundo, sin contar los cientos de miles o millones de objetos que habría que incluir en la categoría del instrumentum domesticum ${ }^{10}$; de ellas, aproximadamente el $75 \%$ eran textos funerarios (Saller - Shaw 1984, 124-156).

Las proporciones inversas que se registran en el conventus $\mathrm{Lu}$ censis traducen la existencia de un hábito epigráfico ${ }^{11}$ mayoritaria-

\footnotetext{
${ }^{10}$ Susini 1982, 25; Saller - Shaw 1984, 124-156 hablan de algo más de 250.000.

${ }^{11}$ Sobre el concepto de hábito epigráfico, esto es, el ritmo de producción de
} 
mente desarrollado al servicio de la religión. Incluso si retiramos de la TABLA 2 los datos relativos al santuario del Lar Berobreus del Facho de Donón (TABLA 3), las inscripciones votivas seguirían representando un $37,89 \%$ del total frente a un $34,29 \%$ de las funerarias.

\begin{tabular}{|c|c|c|c|c|c|}
\hline & Altares & Estelas & Placas & Otros /desconocido & Total \\
\hline n. $^{\circ}$ & 300 & 87 & 13 & 145 & 545 \\
\hline$\%$ & 55,05 & 15,96 & 2,39 & 26,61 & 100,00 \\
\hline
\end{tabular}

TABLA 4 - Tipología de los soportes epigráficos en el conventus Lucensis.

\begin{tabular}{|c|c|c|c|c|c|}
\hline & Altares & Estelas & Placas & Otros /desconocido & Total \\
\hline n. $^{\circ}$ & 172 & 87 & 13 & 145 & 417 \\
\hline$\%$ & 41,25 & 20,86 & 3,12 & 34,77 & 100,00 \\
\hline
\end{tabular}

TABLa 4 - Tipología de los soportes epigráficos en el conventus Lucensis, excluidos los testimonios del Facho de Donón.

Un tercer dato a tener en cuenta es el de la tipología de los monumentos (TABLA 4). Más de la mitad de los identificados, un 55,05\%, son altares. Incluso sin tomar en consideración los procedentes del Facho de Donón, la cifra sigue alcanzando el 41,25\%. La mayor parte de ellos son votivos, pero no faltan los funerarios.

De todo lo anterior puede deducirse que, en términos estadísticos, el tipo más corriente de inscripción romana en el conventus Lucensis es el altar votivo de granito.

La mayor parte de ese conjunto epigráfico del conventus Lucensis debe fecharse entre los siglos I y II, tal y como en otras regiones de Hispania y del Imperio Romano (AlFöldy 1998, 289-301); hace ya varias décadas que esta datación global tiene confirmación estadística (MrozeK 1973, 113-118 y 1988, 61-64) y el noroeste peninsular no es una excepción.

La distribución geográfica de esas inscripciones (FIG. 1) presenta dos ámbitos claros de concentración de testimonios en Lucus Augusti

epígrafes en relación con el grado de latinización y las necesidades generadas por el entorno cultural, vide MacMullen 1982, 233-246 y Meyer 1990, 74-96. Cf. Mrozek 1973, 113-118 y 1988, 61-64.

Conimbriga, 55 (2016) 193-219 
y en el emplazamiento del Facho de Donón, unos de los dos santuarios de la Península Ibérica que presentan un número tan elevado de testimonios epigráficos ${ }^{12}$; no obstante, hay que tener en cuenta que aquí un buen número de ellos son fragmentos de altares en los que no se conserva el texto, mientras que en el santuario de Endovellicus de Terena el número de monumentos con inscripción se acerca al centenar. En términos de reparto geográfico, la mayor concentración de inscripción romanas del conventus Lucensis -fuera de los dos casos citados- se encuentra en la mitad occidental del territorio, especialmente en el cuadrante suroccidental. Un rápido cálculo sobre los $3.696 \mathrm{Km}^{2}$ de la provincia de Pontevedra muestra que el conjunto provincial supera la ratio de 3 inscripciones por cada $100 \mathrm{Km}^{2}$, lo que constituye un valor medio para el conjunto de Hispania ${ }^{13}$. Esas cifras casi duplican las de Lugo y casi triplican las de A Coruña. Una gran parte de estos testimonios proceden de zonas litorales, pero hay concentraciones importantes en los ámbitos de Padrón (Coruña), alrededores de Lalín (Pontevedra), A Estrada, Caldas de Reis y Cuntis (las tres en Pontevedra), etc. En el cuadrante noroccidental del territorio se observa una importante concentración de hallazgos en el área de Santa Comba (A Coruña) y, especialmente, en el espacio delimitado por Santiago de Compostela al oeste, el extremo de la península del Barbanza al oeste y la mencionada zona de Santa Comba al noroeste. En este espacio conocemos inscripciones romanas en casi una treintena de localidades, con varios testimonios en algunas de ellas.

${ }^{12}$ El otro santuario de estas características es el de Endovellicus de São Miguel de Mota (Terena, conc. Alandroal, distrito de Évora). De este lugar procede casi un centenar de textos, incluyendo fragmentos funerarios, algún altar anepígrafo y, sobre todo, la importante colección de invocaciones a esta divinidad prerromana. Sobre este emplazamiento y sus hallazgos epigráficos, vide Lambrino 1951, 93-146; ENCARNAÇÃo 1975, 181-185; Id. 1984, n. ${ }^{\circ}$ 482-565; Alves e Coelho 1995-1997, 233-265; Guerra, Schattner, Fabião, Almeida 2003, 415-479; Eid. 2005, 184-234; Ribeiro 2005, 721 766; ENCARNAÇÃo 2011, 149-163.

${ }^{13}$ La media de Hispania $\left(602.008 \mathrm{Km}^{2}\right)$ está ligeramente por encima de las 3 inscripciones por cada $100 \mathrm{Km}^{2}$; la mayor presencia de inscripciones en relación con la superficie se encuentra al norte de la Tarraconense costera (Tarragona y Barcelona), en el centro-sur de Andalucía (Jaén, Córdoba, Sevilla, Cádiz), norte de Extremadura y de la Meseta (Cáceres y Burgos), sur del País Vasco y norte de Portugal; en todos los casos citados las cifras están por encima de 5 inscripciones por cada $100 \mathrm{Km}^{2}$ (ABASCAL 2002, 271).

Conimbriga, 55 (2016) 193-219 
En el centro - norte de la región existen dos importantes ámbitos de concentración epigráfica. El primero de ellos tiene como extremo septentrional el núcleo de Brigantium (A Coruña) y el perímetro de la zona de hallazgos vendría delimitado por los concellos de Cerceda, Abegondo, Coirós, Betanzos y Oleiros, localidades todas de la misma provincia. El segundo ámbito, más oriental, gravita en torno a Guitiriz (Lugo) y los hallazgos se concentran en una zona situada al sur de Villalba (Lugo), limitada por Guitiriz y Miraz al oeste y sur y por Buriz al norte; este espacio incluye toda la tierra de Parga (Lugo), que parece tener una entidad epigráfica propia.

En las regiones centrales del conventus Lucensis, en la comarca del Alto Tambre, se estableció el campamento de la cohors I Celtiberorum de Sobrado dos Monxes (A Coruña) ${ }^{14}$. La presencia de esta instalación militar está bien documentada por los diversos hallazgos realizados durante las numerosas campañas de excavación llevadas a cabo en este enclave y por el importante conjunto de tégulas que presentan marcas con el nombre de la unidad ${ }^{15}$. El número de inscripciones en piedra localizadas en el área campamental o sus inmediaciones no alcanza la decena ${ }^{16}$, una importancia poco mayor tienen los grafitos cerámicos

${ }^{14}$ Entre la numerosa bibliografía sobre este lugar, véase especialmente CAAMAÑO 1987, 71-78; Id. 1991, 19-22; CAAMAÑo e FERNÁNDEZ 2000, 199-207.

${ }^{15}$ Las marcas de tégulas de la unidad han sido objeto de dos estudios específicos: CAAmaño 1989, 209-228; CAAmaño e Carlsson-Brandt 2015, 107-120. Gracias a la amabilidad de sus excavadores, pudimos revisar y fotografiar todo este conjunto el 24 de febrero de 2016.

${ }^{16}$ CaAmaño 1983, 61-71; Pereira 1991, n. ${ }^{\circ}$ 31-37. Agradezco al Director del Museo Arqueolóxico de A Coruña, D. José María Bello, y a D. ${ }^{a}$ Ana Martínez Arenaz, todas las facilidades dadas para el estudio de las inscripciones romanas conservadas en ese centro y su apoyo para la labor de revisión epigráfica. Estoy en deuda también con los responsables de las excavaciones en el campamento de Cidadela, D. José Manuel Caamaño Gesto y D. Erik Carlsson-Brandt Fontán, por su autorización para revisar estos materiales y hago extensiva esa gratitud a D. Ramón Izquierdo, Director del Museo de la catedral de Santiago, por la autorización y la ayuda para realizar la revisión y las fotografías de las inscripciones conservadas en ese fondo, trabajo que llevamos a cabo en sendas visitas del año 2015. Una de los textos de Cidadela se conserva en el Museo do Povo Galego en Santiago de Compostela, en donde quiero agradecer a D. ${ }^{a}$ Belén Sáenz-Chas Díaz su apoyo permanente para el estudio de esta y de las demás inscripciones romanas que alberga esa institución.

Conimbriga, 55 (2016) 193-219 
recuperados en este lugar ${ }^{17}$, y en los alrededores sólo conocemos actividad epigráfica en las localidades coruñesas de San Vicente de Présares (conc. Vilasantar) ${ }^{18}$ y Toques ${ }^{19}$. Es difícil explicar este vacío epigráfico si no es porque una gran parte del territorio circundante al campamento quedara bajo la jurisdicción del ejército.

La observación de la Fig. 1 permite distinguir varias zonas del conventus en las que la actividad epigráfica es mínima o nula. Eso sucede en toda la costa coruñesa comprendida entre Laxe ${ }^{20}$ al norte y Fisterra $^{21}$ al sur, incluyendo las tierras interiores hasta Tines y Brandomil (A Coruña). El vacío epigráfico se repite en gran parte del norte de las provincias de A Coruña y Lugo; en la primera no hay hallazgos al

${ }^{17}$ LÓPEZ PÉRez 2004, n. ${ }^{\circ}$ 456, 678, 680, 682, 685, 688, 691 y 698 (HEp 13, 2003/2004, 323-330). Otros fragmentos inéditos se conservan en el Museo Arqueolóxico de A Coruña.

${ }^{18}$ Se trata de una dedicación a las Ninfas realizada por Reburrius Tertius. Cf. PEREIRA 1991, n. ${ }^{\circ}$ 38, con la bibliografía anterior. La revisión de la inscripción se llevó a cabo en el Museo de A Coruña el 25 de junio de 2015 con la ayuda del Dr. Juan Carlos Olivares.

${ }^{19}$ El epígrafe procedente de la villa romana de Melide (Toques, A Coruña) es un pequeño altar dedicado a Mercurio, elaborado en una piedra local conocida con el nombre de "Piedra de Tobelo" o "Piedra de Murcia". Cf. Rabanal et alii 1996, 68-69 nota 231 (HEp 7, 1997, 317); Rodríguez e AcuÑa 1999, 326. Agradezco a D. José Manuel Broz, Director del Museo da Terra de Melide, su información sobre el tipo de piedra del soporte así como las facilidades que nos dio para estudiar y fotografiar el monumento el día 7 de febrero de 2016.

${ }^{20}$ El epígrafe que permite establecer este "límite" septentrional es un altar a Cosus que se encuentra empotrado en el contrafuerte del muro meridional de la iglesia parroquial de Serantes, al sur del concello de Laxe (CASTILlo e D'Ors 1959, 152 n. $^{\circ}$ 9; Eid. 1960, 12 n. ${ }^{\circ} 9$ [= HAE 1704; Vives ILER 790]; PereIRA 1991, 183 n. ${ }^{\circ} 70$, que la da por perdida). El estado de conservación es aceptable, como pudimos comprobar en la revisión llevada a cabo el 24 de abril de 2016.

${ }^{21}$ De Sardiñeiro, en el concello de Fisterra, procede un altar de granito cuya lectura presenta plantea algunas dudas. En la edición original (CASTILlo e D'Ors 1959, 150 n. ${ }^{\circ}$ 6; Eid. 1960, 10 n. ${ }^{\circ} 6$ [= HAE 1701r; Vives ILER 980]) se leyó Mard-/umus / et Val(eria ?) e(x) / voto. Sin embargo, la autopsia llevada a cabo antes de 1991 por G. Pereira llevó a este autor a sugerir que hubiera que leer Matri De-/um s(acrum) +(- - -) / et Val(- - -) e (x) / voto (PereIRA 1991, 185 n..$^{\circ} 71$ [= HEp 4, 1994, 331]), con lo que se trataría de una dedicación a Cibeles. La cuestión no puede resolverse debido a la pérdida del monumento y a la ausencia de fotografías. Sobre el culto a Cibeles en Gallaecia vide Tranoy 1981, 334.

Conimbriga, 55 (2016) 193-219 
norte de As Pontes de García Rodríguez ${ }^{22}$ y en la segunda, por encima de $\mathrm{Miñotos}^{23}$, sólo hay un hallazgo aislado en $\mathrm{Cervo}^{24}$; en el nordeste de esta última provincia, el hábito epigráfico está representado sólo por algunos hallazgos aislados en la zona de Mondoñedo.

Un vacío más inexplicable aún es el de las regiones nororientales del conventus Lucensis, es decir, de las tierras de Asturias situadas al occidente del río Navia. En la margen derecha del río Eo contamos sólo con la estela de La Corredoira, cerca de Vegadeo; en la margen izquierda del Navia se encuentran los hallazgos de Coaña y el importante conjunto epigráfico de Grandas de Salime. Pese a que en el caso de Ve-

${ }^{22}$ De aquí procede el conocido epígrafe con el testimonio del oráculo de Apolo de Claros; $c f$. Montero 1989, 357-364 (AE 1990, 545) e Id., 2003, 123-130); Pereira 1991, 163-164 n. ${ }^{\circ}$ 60. El altar se encuentra en el pórtico de la casa do concello de As Pontes de García Rodríguez, donde pudimos verlo y estudiarlo el día 11 de octubre de 2015 en compañía de D. Juan Carlos Olivares (Univ. de Alicante) y D. Antonio Castro, concejal de este ayuntamiento, a quien quiero agradecer su ayuda y compañía en las dos visitas que hemos realizado a esta localidad. De este concello procede un segundo altar, esta vez dedicado a los Lares Viales (AE 2005, 845; HEp 14, 2005, 168), que se encuentra en la iglesia de San Mamede, en Somede, al nordeste de As Pontes; allí pudimos verlo y fotografiarlo el 3 de febrero de 2016 en compañía de Antonio Castro y Sonia Sueiro (concello de As Pontes) y de Pilar González-Conde (Univ. de Alicante).

${ }^{23}$ La parroquia de Miñotos (conc. de Ourol) ha proporcionado hasta el momento la parte superior de un altar dedicado a los Lares Viales (Rodríguez Colmenero et alii 2004, 723 n. ${ }^{\circ}$ 664; HEp 13, 2003/2004, 437) que se conserva en el Seminario de Estudios "Terras de Viveiro" en Viveiro. Allí pudimos verla y fotografiarla el 5 de febrero de 2016. Agradezco a los responsables de esta institución, especialmente a D. Carlos Nuevo, sus atenciones y las facilidades para documentar la pieza.

${ }^{24}$ Sobre el monumento, vide RodríGuez Colmenero et alii 2004, 724 n. ${ }^{\circ} 665$ (HEp 13, 2003/2004, 425). Este altar a los Lares Viales se conserva en el Museo de Lugo, donde pudimos verlo y fotografiarlo el 23 de junio de 2015. El trabajo de revisión de las inscripciones lucenses para la redacción del correspondiente fascículo del Corpus Inscriptionum Latinarum ( $\left.C I L \mathrm{II}^{2} / 9\right)$ ha sido posible gracias al permanente apoyo de los responsables institucionales, de los técnicos de los Museos y del Ayuntamiento de Lugo, de los expertos en la epigrafía de la región, así como de los autores de las excavaciones. Quiero expresar mi gratitud por ello a D. Antonio Rodríguez Colmenero (Universidad de Santiago de Compostela. Campus de Lugo), D. ${ }^{a}$ Aurelia Balseiro García (Directora del Museo de Lugo), D. a Covadonga Carreño Gascón y D. Enrique González Fernández (Servicio de Arqueología del Ayuntamiento de Lugo), D. Enrique J. Alcorta Irastorza y D. ${ }^{a}$ Ofelia Carnero Vázquez (Museo de Lugo), D. César Carnero y D. ${ }^{a}$ Carolina Casal (Museo Diocesano de Lugo) y a D. Francisco Herves (arqueólogo).

Conimbriga, 55 (2016) 193-219 
gadeo estamos ante la estela de un princeps Albionum ${ }^{25}$ y que de Grandas de Salime procede la conocida placa de pizarra con un rico registro onomástico ${ }^{26}$, ambas piezas y las de Coaña ${ }^{27}$ no justifican por sí solas el hábito epigráfico de una región tan densamente poblada desde el punto de vista de la ocupación castreña. A todas luces, habría que aceptar que, al menos en los dos siglos primeros de la Era, en esta zona hubo una tímida implantación de la lengua latina y de todo lo que ella acarreaba ${ }^{28}$.

La fundación y desarrollo de la ciudad de Lucus Augusti dio lugar a una intensa actividad epigráfica que se pone de manifiesto en el hallazgo en el ámbito urbano de casi un centenar de inscripciones; a ellas hay que añadir un importante conjunto de objetos amparados bajo la categoría de los instrumenta domestica y un buen número de grafitos cerámicos de cierta entidad. Hübner ya había reconocido en esta ciudad un total de 25 inscripciones en agosto de 1861 (ABASCAL 2015b, 89-94); desde entonces el número de hallazgos no ha cesado de incrementarse debido a los descubrimientos casuales y, ya en época más reciente, a las excavaciones arqueológicas. Al importante valor de la serie hay que unir el concienzudo trabajo de recuperación y custodia de las inscripciones llevado a cabo en el último siglo en esta ciudad, lo que hace que sus colecciones sean hoy modélicas ${ }^{29}$. La localidad alberga algunos conjuntos epigráficos del máximo interés entre los que se cuenta el ninfeo del balneario situado junto al río Miño, en donde hay que esperar aún nuevos descubrimientos si algún día se reanudan las excavacio-

${ }^{25}$ Diego 1985, 71-73 n. ${ }^{\circ}$ 14; Monteagudo 1999, 78; Villa 2013, 181 y 183. Pudimos describir y fotografiar esta pieza el 26 de febrero de 2016 gracias a la amabilidad y a la ayuda de D. Ángel Villa Valdés (Museo de Asturias), a quien queremos expresar nuestra gratitud por ello.

${ }^{26}$ Villa, Francisco e Alföldy 2005, 271-274 (HEp 14, 2005, 21); FrancisCO, Alföldy e Villa 2009, 246-247 (HEp 18, 2009, 21); Villa 2009b, 20-21 Fig. 16. La autopsia de la pieza se realizó el 26 de febrero de 2016 en el Museo de Asturias en compañía de A. Villa Valdés y M. ${ }^{a}$ P. González-Conde (Univ. de Alicante).

${ }^{27}$ Diego 1985, 211-212 n. ${ }^{\circ}$ 66; Villa VAldÉs 2007, 413-418; Id. 2013, 139-187.

${ }^{28}$ Sobre este tema, vide especialmente Díaz y Díaz 1983, 283-293; sobre la latinización de Hispania en general, cf. CARNOY 1906/1971; GARCía y Bellido 1967, 3-29; MAYER 1994, 363-382.

${ }^{29}$ Una visión general de la historia de la ciudad, con comentarios e imágenes de los hallazgos arqueológicos más significativos, puede verse en la síntesis de RODRÍGUEZ COLMENERo 2011.

Conimbriga, 55 (2016) 193-219 
nes $^{30}$, o el mitreo situado junto a la catedral, de donde procede uno de los epígrafes más importantes de Galicia (FIG. 2a) ${ }^{31}$. Entre las piezas singulares procedentes de esta ciudad hay que citar también cinco altares dedicados a Júpiter, los dedicados a numerosas divinidades indígenas (Lahus Paraliomegus, Reus Paramaecus, etc.) o el altar funerario de la ornatrix Philtates (FIG. 2b) ${ }^{32}$.

En los altares lucenses destaca por su singularidad el dedicado a Verora por Rufus (FIG. 3a) ${ }^{33}$. Se trata de un monumento de granito, de $80 \mathrm{~cm}$ de altura, cuyo focus circular está protegido por una hornacina excavada dentro de un frontón triangular. La solución es idónea para la exposición a la intemperie, ya que la hornacina protegía la combustión del viento o de la lluvia e impedía, al mismo tiempo, la dispersión de cenizas. La solución adoptada en Lugo se repite en un altar dedicado a Venus Victrix en Aquae Flaviae (Chaves) (FIG. 3b) ${ }^{34}$, lo que debe entenderse en el ámbito de los contactos regionales entre los talleres lapidarios de las grandes ciudades del noroeste o en el ámbito de las modas extendidas por artesanos itinerantes. Lo más llamativo es que ambos altares guardan una cierta relación estética con algunos de los monumentos recuperados en el santuario del deus Lar Berobreus del Facho de Donón (O Hío, Pontevedra) y, especialmente, con uno de grandes dimensiones $(164 \mathrm{~cm})$ en cuya parte superior figura también un frontón triangular excavado (FIG. 3c) ${ }^{35}$; evidentemente, se trata de una pieza ne-

${ }^{30}$ Debe tenerse en cuenta que la zona excavada es sólo una parte de la estructura original. Las inscripciones están publicadas en Herves e MeJide 2000, 187-196. Una valoración general del lugar se encuentra en GonZÁLEz Soutelo 2012, 167-182.

${ }^{31}$ Rodríguez Colmenero e RodríGuez CaO 2007, 219-221; Alvar et alii 2006, 267-277. Agradezco a D. Celso Rodríguez Cao las facilidades para documentar esta inscripción en junio de 2015.

${ }^{32}$ EE VIII 311; Degrassi 1963/1978, 51-56 y 298-303; ArIas, Le Roux e Tranoy 1979, 58-59 n. ${ }^{\circ} 32$; AlFöLDY 2001, 233-238, con el resto de la bibliografía (de ahí, $A E$ 2001, 1213 y HEp 11, 2001, 320).

${ }^{33}$ CIL II 2576; Vázquez Saco e Vázquez Seijas 1954, 33 n. ${ }^{\circ} 13$ (Vives ILER 953); Arias, Le Roux e Tranoy 1979, 39 n. ${ }^{\circ}$ 12; Ares 2014, 28-29.

${ }^{34}$ VASCONCELOS 1927-1929, 142-144 (AE 1933, 23). FernáNDEZ Fuster 1950, 282-283 (HAE 34); RuSSELl 1957, 101-102 n. ${ }^{\circ}$ 4; VIVES ILER 415; RODRÍGUEZ Colmenero 1987 n. $^{\circ}$ 67; Ares 2014, 29.

${ }_{35}$ Baños 1994, 27 n. 1 (AE 1994, 942); Baños e Pereira 1998, 22 n. ${ }^{o} 1$ (HEp 6, 1996, 712); Rodríguez Colmenero 1997, 390-391 (HEp 7, 1997, 569); SCHATtNer, SuÁrez e Koch 2004, 35 lám 5c. Pudimos describir y fotografiar la pieza el 21 de 
tamente posterior a las de Lucus Augusti y Aquae Flaviae, que no deben rebasar los años centrales del siglo II. El altar pontevedrés parece imitar de manera tosca esos prototipos más antiguos que eran ya conocidos en la región y, en su posición original clavado en el suelo, permitiría lo que Susini llamó el "golpe de vista" epigráfico (Susini 1982, 23), es decir, la percepción global de lo imprescindible para asegurar la comprensión del tipo de epígrafe y de su contenido.

Si hablamos de altares votivos del conventus Lucensis, no podemos dejar de citar por su envergadura el dedicado a Neptuno en Padrón (A Coruña ${ }^{36}$, hoy conservado bajo el altar mayor de la iglesia de Santiago y conocido popularmente como "El Pedrón", el cipo al que habría atado el barco el apóstol Santiago con ocasión de su venida a Galicia (FIg. 4). El monumento alcanza los $172 \mathrm{~cm}$ de altura (!) y su primera línea está casi borrada para sustituirla por una cruz. Pese a ello, la lectura del teónimo Nept/[u]no no ofrece dificultades. Las letras de la parte inferior presentan restos de pintura aplicada en época moderna y su lectura no ha estado exenta de polémica por la hipotética presencia ahí de un gentilicio referido al topónimo de Iria Flavia mencionado en Ptolomeo $(2,6,33)$.

En el ámbito de las estelas, el grupo más interesante del conventus es el que muestra representaciones antropomorfas y entre todas ellas destaca el soberbio ejemplar de San Pedro de Mera que conserva el Museo de Lugo (FIg. 5a) ${ }^{37}$. Sus $281 \mathrm{~cm}$ de altura hacen de ella una de las estelas más grandes del Imperio Romano y el grupo escultórico de

agosto de 2015 en el Museo de Pontevedra. Quiero expresar nuestra gratitud a D. Carlos Valle y a D. Antonio de la Peña por su acogida y por todas las facilidades que nos dieron para documentar la colección epigráfica del Museo.

${ }^{36}$ Murguía 1966, vol. 2, 22; CIL II 5626 (= II 2540); Castillo e D’Ors 1959, 147-148 n. ${ }^{\circ}$ 2; Eid. 1960, 7-8 n. 2 (Vives ILER 155); Pereira 1991, $49-50$ n. ${ }^{\circ} 12$; Rodríguez Colmenero et alii 2004, 598 n. ${ }^{\circ}$ 522. Pudimos ver el monumento el 26 de abril de 2016 gracias a la amabilidad de D. Roberto, párroco de la iglesia de Santiago.

${ }^{37}$ Rodríguez Colmenero e CARreÑo 1996, 283-288 (AE 1997, 863; HEp 7, 1997, 397); Rodríguez Colmenero 1997-1998, 79-90; Alcorta 2007, lám. XXI. Pudimos estudiar y fotografiar la pieza el día 24 de junio de 2016 gracias a la hospitalidad y ayuda del equipo humano del Museo. La discusión bibliográfica sobre el valor de la $C$ invertida en este texto carece ya de sentido, toda vez que el debate quedó resuelto hace mucho tiempo; cf. Pereira 1982, 249-267; Le Roux e Tranoy 1983, 109-212; la cuestión está resumida en Brañas 2004, 155-205, que presenta un apéndice epigráfico con todos los testimonios de $C$ invertida.

Conimbriga, 55 (2016) 193-219 
su cabecera destaca claramente por su realismo en la serie de representaciones funerarias que conocemos en Gallaecia y, específicamente, en el conventus Lucensis. El resto de los ejemplares (FIG. 5b-g) ofrece imágenes muy toscas, con representaciones frontales de estilo casi naïf (FIG. 6b-c, e-g) de las que sólo se exceptúa la estela que muestra al difunto acompañado de su caballo y del que se dice que murió en el valle del Miño (FIG. 6d) ${ }^{38}$. A este grupo habría que unir aquellas estelas que, específicamente, se asemejan a representaciones antropomorfas, como ocurre por ejemplo con las de Tines (A Coruña) o Paradela (Pontevedra) $)^{39}$.

En términos generales, y pese a los vacíos epigráficos de determinadas zonas y al desigual reparto geográfico, la producción epigráfica del conventus Lucensis muestra una gran riqueza formal y, sobre todo, una extraordinaria diversidad en los contenidos si se compara con otras regiones peninsulares. Como ha demostrado la tradición científica de los últimos ciento cincuenta años - y como siguen mostrando los nuevos hallazgos - nuestro mayor campo de ensayo epigráfico en este ámbito sigue siendo el de los textos votivos, donde el panteón de Gallaecia se muestra con plena vitalidad pese a que la muestra que ha llegado a nosotros debe rebasar en muchos casos el siglo II. Ese empleo del latín epigráfico en la práctica religiosa relacionada con el panteón indígena $\mathrm{y}$, sobre todo, el abultado número de grafitos cerámicos que van apareciendo en los últimos años, evidencian que la escritura fue en el conventus Lucensis una práctica generalizada, muy extendida y no restringida a determinados grupos sociales ${ }^{40}$. Además, la presencia de inscripciones en objetos de uso cotidiano no cerámicos, muestra una estrecha cercanía entre la población y la actividad epigráfica. El uso

${ }^{38}$ BALIL 1983, 179-184, con la bibliografía anterior; Pereira 1991, 99-100 n. ${ }^{\circ}$ 34. Se conserva en el Museo de la catedral de Santiago de Compostela, donde pudimos verla y fotogrfiarla el 18 de agosto de 2015 por cortesía de su Director, D. Ramón Izquierdo.

${ }^{39}$ Sobre este tipo de monumentos debe consultarse el trabajo de síntesis de RoDRÍGUEZ ÁLVAREZ 1981, 73-82.

${ }^{40}$ Ya no parece viable la impresión recogida hace más de dos décadas en ARIAS 1991, 26: "semella estar claro que o uso de pedras con epígrafe en latín corresponde, maiormente e con tódalas excepcións que se queiran aducir, ós grupos sociais ou á casta social más romanizada, ben de orixe foránea, ben do que se deu en chamar comunidade indíxena 'colaboracionista', en gran medida ademáis, presuntamente indíxena-falante".

Conimbriga, 55 (2016) 193-219 
mayoritario del granito permitió en esta región tener acceso a un material que se encontraba en cualquier lugar, barato y fácil de trabajar incluso para manos no expertas, lo que permitió desarrollar el hábito epigráfico incluso fuera de los talleres y officinae que estamos acostumbrados a ver en otros ámbitos geográficos. Si exceptuamos la ciudad de Lucus Augusti, cuyo comportamiento epigráfico está más estandarizado en relación con el de otros centros urbanos de Hispania y del Imperio Romano, la epigrafía del conventus Lucensis sólo tímidamente recoge modas y estilos desarrollados en otras regiones, lo que hace de este repertorio un catálogo de la creatividad local al servicio de las necesidades cotidianas.

\section{BIBLIOGRAFÍA}

Abascal, J. M. (2002): "Fasti consulares, fasti locales y horologia en la epigrafía de Hispania”, AEspA 75, 269-286.

ABASCAL, J. M. (2003): "La recepción de la cultura epigráfica romana en Hispania”, en De Iberia in Hispaniam. La adaptación de las sociedades ibéricas a los modelos romanos, Alicante, 241-286.

Abascal, J. M. (2015a): "Una perspectiva administrativa de la Hispania de Augusto", en J. López VILAR (Ed.), Actes 2on Congrés Internacional d'Arqueologia i món antic. August y les províncies occidentals. 2000 aniversari de la mort d'August. Tarragona, 26-29 de novembre de 2014, Tarragona, vol. 1, 129-140.

AbasCal, J. M. (2015b): Estudios sobre la tradición manuscrita de la epigrafía hispano-romana, Madrid.

AlARCÃo, J. de (1998): “Ainda sobre a localização dos populi do conventus Bracaraugustanus", Anales de Arqueología Cordobesa 9, 51-57.

- (2003): "As estátuas de guerreiros galaicos como representações de príncipes no contexto da organização político-administrativa do noroeste pré-flaviano", $\operatorname{MDAI}(M)$ 44, 116-126.

Alcorta, E. et alii (2007): Guía gráfica do Museo Provincial de Lugo, A Coruña.

ALFöLDY, G. (1998): "La cultura epigráfica de la Hispania romana: inscripciones, auto-representación y orden social”, en Hispania, el legado de Roma, Zaragoza, 289-301.

ALFÖLDY, G. (2001/2002): "Eine clarissima femina in Lucus Augusti”, ZPE 136, 2001, 233-238 (Traducido como capítulo 3 en el volumen de G. AlföLdy, Provincia Hispania superior, A Coruña 2002, 81-91).

Alvar, J., Gordon, R. e Rodríguez CaO, C. (2006), "The Mithraeum at Lugo (Lucus Augusti) and its connection with legio VII Gemina", Journal of Roman Archaeo$\log y$ 19, 267-277.

Conimbriga, 55 (2016) 193-219 
Álvarez Asorey, R. (2001): "El límite oceánico de separación entre el conventus Lucensis y el Bracarensis a partir del estudio de los miliarios de la vía XIX del Itinerario de Antonino", Larouco 3, (= Homenaxe póstumo a Victoriano Reinoso. Actas do Simposio Internacional sobre a Rede Viaria Romana, Porto Quintela. Bande, septiembre de 2001), 169-176.

Alves Dias, M. M. e Coelho, L., 1995-1997, "Endovélico: caracterização social da romanidade dos cultuantes e do seu santuário (São Miguel de Mota, Terena, Alandroal)", $A P$ série 4, vol. 13-15, 233-265.

Ares VÁzquez, N. (2014): “Ara dedicada a Venus Victoriosa en Chaves”, CROA [Castro de Viladonga] 24, 28-29.

Arias Vilas, F. (1991): "Xacementos arqueolóxicos e achados epigráficos en Galicia", Cuadernos de Estudios Gallegos 39 n. ${ }^{\circ}$ 104, 23-33.

Arias, F., Le Roux, P. e Tranoy, A. (1979): Inscriptions romaines de la province de Lugo, Paris.

Baños, G. (1994): Corpus de inscricións romanas de Galicia I. Provincia de Pontevedra, Santiago de Compostela.

BaÑos, G. - Pereira, G. (1998): "Deus Larius Brus Sanctus. Las inscripciones votivas del Facho de Donón (Pontevedra)", en Homenaje a José M. ${ }^{a}$ Blázquez V (ARYS $\mathrm{n}^{\mathrm{o}}$ 2), Madrid, 21-44.

Brañas AbaD, R. (2004): “A sociedade castrexa a través da epigrafía”, Cuadernos de Estudios Gallegos 51, fasc. 117, 155-205.

CaAmaño Gesto, J. M. (1983): “Aportaciones al estudio de la cohors I Celtiberorum: una inscripción militar hallada en el campamento romano de Cidadela (Sobrado dos Monxes-Coruña)", Brigantium 4, 61-71.

Caamaño Gesto, J. M. (1987): "La cohors I Celtiberorum y su campamento de Cidadela (Sobrado dos Monxes - Coruña)", Cuadernos de Estudios Gallegos 35, $71-78$.

CAAmaño Gesto, J. M. (1989): "Estampillas de la cohors I Celtiberorum halladas en el campamento romano de Cidadela”, Gallaecia 11, 209-228.

CaAmaño Gesto, J. M. (1991): "El ejército bajo imperial romano en Hispania: el campamento de la cohors I Celtiberorum", en Ciudad y torre. Roma y la Ilustración en La Coruña, La Coruña, 19-22.

CaAmaño Gesto, J. M. e Carlsson-Brandt Fontán, E. (2015): "Marcas de la cohors I Celtiberorum halladas en el campamento romano de Cidadela (Sobrado dos Monxes, A Coruña)", Portugalia, nova série, vol. 36, 107-120.

CaAmaño Gesto, J. M. e Fernández RodríGuez, C. (2000): "Excavaciones en el campamento romano de Cidadela (A Coruña)", Brigantium 12, 199-207.

CARnoy, A. (1971): Le latin d'Espagne d'après les inscriptions, Bruxelles 1906 (1971²).

Castillo, A. Del e D’Ors, A. (1959/1960): Inscripciones romanas de Galicia. Suplemento al fascículo I. Provincia de La Coruña, Santiago de Compostela 1960 (previamente publicado en Cuadernos de Estudios Gallegos 14, 1959, 145-164).

Curchin, L. A. (2008): "Los topónimos de la Galicia romana: nuevo estudio", Cuadernos de Estudios Gallegos 55 n. ${ }^{\circ}$ 121, 109-136.

Conimbriga, 55 (2016) 193-219 
Degrassi, A. (1963/1978): “Un torinese relegato a Lucus Augusti delle Spagna”, en Atti del I Congresso Internazionale di Archeologia dell'Italia settentrionale. Torino 1961, Torino 1963, 51-56 (Traducido en "Un turinés relegado a Lucus Augusti (España)", Boletín de la Comisión Provincial de Monumentos Históricos y Artísticos de Lugo 9, n. $\left.{ }^{\circ} 85-86,1978,298-303\right)$.

DíAZ y DíAz, M. C. (1983): "Sobre la implantación del latín en la sociedad galaico-romana", en Estudos de Cultura Castrexa e de Historia Antiga de Galicia, Santiago de Compostela, 283-293.

Diego Santos, F. (1985): Epigrafía romana de Asturias, Oviedo.

EnCARnaÇÃo, J. de (1975): Divinidades indígenas sob o dominio romano em Portugal. Subsídios p0ara o seu estudo, Lisboa 1975 (2. ${ }^{\text {a }}$ ed. Coimbra 2015).

EnCARnaÇão, J. de (1984): Inscrições romanas do conventus Pacensis, Coimbra.

EnCARnAÇÃo, J. de (2011): "Endovélico - 400 anos depois", en J. Cardim Ribeiro (coord.), Diis - Deabusque. Actas do II Colóquio Internacional de Epigrafia «Culto e Sociedade». Sintra, 16-18.03.1995 (Sintria III-IV, 1995-2007), São Miguel de Odrinhas, 149-163.

Estefanía Álvvarez, M. del D. N. (1958): "Notas para la delimitación de los conventos jurídicos en España”, Zephyrus 9, 51-57.

Fariña Busto, F. e SuÁrez Otero, J. (2002): "El santuario galaico-romano de O Facho (O Hío, Pontevedra), Boletín Auriense 32, 25-52.

FERNÁNDEZ Fuster, L. (1950): "La fórmula ex-visu en la epigrafía hispánica", AEspA 23, n. $^{\circ} 80,279-291$.

Francisco Martín, J., Alföldy, G. e Villa ValdÉs, Á. (2009): «58. Inscripción censal», en ViLLA VALDÉs 2009a, 246-247.

Franco Maside, R. M. (2001): "La via per loca maritima, un estudio sobre vías romanas en la mitad noroccidental de Galicia”, Gallaecia 20, 217-248.

García y Bellido, A. (1967): "La latinización de Hispania", AEspA 40, 3-29 (= Die Latinisierung Hispanien, $A N R W$ I. 1, 1972, 462-500).

GonzÁLEz Soutelo, S. (2012): "El balneario romano de Lugo: una nueva interpretación arquitectónica y funcional”, Saguntum 44, 167-182.

Guerra, A., Schattner, Th. G., Fabião, C. e Almeida, R. (2003): "Novas investigações no santuário de Endovélico (S. Miguel de Mota, Alandroal): a campanha de 2002", Revista Portuguesa de Arqueologia 6.2, 415-479.

Guerra, A., Schattner, Th. G., Fabĩ̃o, C. e Almeida, R. (2005): “São Miguel da Mota (Alandroal, Portugal), 2002. Bericht über die Ausgrabungen im Heiligtum des Endovellicus", $\operatorname{MDAI}(M)$ 46, 2005, 184-234.

Herves Raigoso, F. - Mejide Cameselle, G. (2000), O culto das Ninfas nas termas de Lugo, Gallaecia 19, 187-196.

Koсн, M. (2005): "El santuario dedicado a Berobreo en el Monte do Facho (Cangas, Galicia)", en Acta Palaeohispanica IX. Actas del IX Coloquio sobre lenguas y culturas paleohispánicas (Palaeohispanica 5, 2005), Zaragoza, 823- 836.

Lambrino, S. (1951): "Le dieu lusitanien Endovellicus", Bulletin des Études Portugaises et de l'Institut Français au Portugal 15, 93-146.

Conimbriga, 55 (2016) 193-219 
Le Roux, P. e Tranoy, A. (1983): “ $C$, le mot et la chose. Contribution au débat historiographique", AEspA 56, 109-212.

LÓPEZ PÉREZ, M. C. (2004): El comercio de terra sigillata en la provincia de A Coruña (Brigantium 16), A Coruña.

MacMullen, R. (1982): "The Epigraphic Habit in the Roman Empire”, AJPh 103, 233-246.

MAYer, M. (1994): "El latín de Hispania”, Actas del VIII Congreso Español de Estudios Clásicos, Madrid 1991, Madrid, vol. 1, 363-382.

Meyer, E. A. (1990): "Explaining the Epigraphic Habite in the Roman Empire", JRS 80, 74-96.

Monteagudo García, L. (1999): "Populi y castella en el edicto de Bembibre”, Bierzo - León, Anuario Brigantino 22, 71-82.

Montero Herrero, S. (1989): "Un oráculo del Apolo de Claros en Galicia”, en Estudios sobre la Antigüedad en Homenaje al profesor Santiago Montero Díaz (Anejos de Gerión 2), Madrid, 357-364 (= Id., "Un oráculo del Apolo de Claros en As Pontes", en V. Alonso Troncoso (ed.), Patrimomio histórico de As Pontes de García Rodríguez, La Coruña 2003, 123-130).

MrozeK, S. (1973/1988): “A propos de la répartition chronologique des inscriptions latines dans le Haut Empire”, Epigraphica 35, 1973, 113-118 y Epigraphica 50, 1988, 61-64.

Murguía, M. (1866): Historia de Galicia, Lugo.

OzcáRIz GIL, P. (2013): La administración de la provincia Hispania citerior durante el Alto Imperio romano (Instrumenta, 44). Barcelona.

Pereira, G. (1982): "Los castella y las comunidades de Galicia”, Zephyrus 34-35, 249-267.

Pereira Menaut, G. (1991): Corpus de inscricións romanas de Galicia I. Provincia de A Coruña, Santiago de Compostela.

Rabanal, M. A., García Martínez, S. M. a e Hernández Guerra, L. (1996): "La religión y la religiosidad indígeno-romana en el Conventus Lucensis”, Estudios Humanísticos 18, 39-82.

Ribeiro, J. CARDim. (2005): "O Deus Sanctus Endovellicus durante a romanidade, ¿uma interpretatio local de Faunus Silvanus?", en Acta Palaeohispanica IX. Actas del IX Coloquio sobre lenguas y culturas paleohispánicas (Palaeohispanica 5, 2005), Zaragoza, 721-766

Rodríguez Álvarez, M. ${ }^{a}$ P. (1981): "Sincretismo de la religión indígena y la religión romana visto a través de las estelas antropomorfas", Brigantium 2, 73-82.

Rodríguez Colmenero, A. (1972): "Aspectos geográfico-históricos en torno al convento jurídico Bracaraugustano", HAnt 2, 135-163.

Rodríguez Colmenero, A. (1987): Aquae Flaviae I: Fontes epigráficas, Chaves.

Rodríguez Colmenero, A. (1997): "Mougás y Donón: dos santuarios rurales galaicos-romanos del litoral atlántico", El Museo de Pontevedra 51 (Homenaxe a Xosé Filgueira Valverde), 381-411.

Rodríguez Colmenero, A. (1997-1998): “Sobre dos nuevas estelas monumentales de 
Lucus Augusti", Boletín del Museo Provincial de Lugo 8, 79-90 (también publicado en F. Villar - F. Beltrán (eds.), Pueblos, lenguas y escrituras en la Hispania prerromana. Actas del VII Coloquio sobre lenguas y culturas paleohispánicas. Zaragoza, 12 a 15 de marzo de 1997, Salamanca 1999, 605-617).

Rodríguez Colmenero, A. (2011): Lucus Augusti, la ciudad romano-germánica del Finisterre ibérico. Génesis y evolución histórica (14 a.C. - 711 d. C.), Lugo.

Rodríguez Colmenero, A. e CARreño, M. ${ }^{\text {a C }}$ (1996): "Estela romana, monumental, de Crecente (Lugo)", Larouco 2, 283-288 (AE 1997, 863; HEp 7, 1997, 397).

Rodríguez Colmenero, A., Ferrer Sierra, S. e Álvarez Asorey, R. D. (2004): Miliarios e outras inscricións viarias romanas do noroeste hispánico (conventos Bracarense, Lucense e Asturicense), Santiago de Compostela.

Rodríguez Colmenero, A. e Rodríguez CaO, C., 2007, "Un mithraeum en Lucus Augusti", Larouco 4, 219-221.

Rodríguez García, P. e Acuña Castroviejo, F. (1999): “Culto e imagen a Mercurio en Gallaecia", en M. J. BARroca (coord.), Carlos Alberto Ferreira de Almeida in memoriam, vol. II, Porto, 325-331.

Romero Masia, A. M. ${ }^{\mathrm{a}}$ e Pose Mesura, X. M. (1988): Galicia nos textos clásicos (Monografías urxentes do Museu n. $\left.{ }^{\circ} 3\right)$, A Coruña.

Russell Cortez, F. (1957): "Lápides romanas do Museu de Chaves”, Viriatis 1.2, 99 113.

SÁez TABOAdA, B. (2002): “Aportaciones al trazado de la vía 19 del Itinerario de Antonino a su paso por Galicia", Spal 11, 389-408.

SAller, R. e Shaw, B. (1984): "Tombstones and Roman Family Relations in the Principate: Civilians, Soldiers and Slaves", JRS 74, 124-156.

Schattner, Th. G., Suárez Otero, J. e Koch, M. (2004): “Monte do Facho, Donón (O Hío / Prov. de Pontevedra) 2004. Informe sobre las excavaciones en el santuario de Berobreo", AEspA 77 n. ${ }^{\circ}$ 189-190, 23-71.

Schattner, Th. G., SuÁrez Otero, J. e Koch, M. (2005): “Monte do Facho 2003. Bricht über die Ausgrabungen im Heiligtum des Berobreus", $M D A I(M)$ 46, 135-183.

Schattner, Th. G., SuÁrez Otero, J. e Koch, M. (2006a): "Monte do Facho (O Hío / Prov. de Pontevedra) 2004. Bericht über die Ausgrabungen im Heiligtum des Berobreus", MDAI(M) 47, 169-192.

Schattner, Th. G., SuÁrez Otero, J. e Koch, M. (2006b): “Monte do Facho (O Hío / Prov. Pontevedra) 2004. Informe sobre las excavaciones en el santuario de Berobreus", Palaeohispanica 6, 183-223.

Schattner, Th. G., SuÁrez Otero, J. e Koch, M. (2014): "Weihaltäre im Heiligtum des deus lar Berobreus auf dem Monte do Facho (O Hío, Galicien)”, en A. W. Busch - A. Schäfer (eds.), Römische Weihealtäre im Kontext. Internationale Tagung in Köln vom 3. bis zum 5. Dezember 2009 'Weihealtäre in Tempeln und Heiligtümern', Friedbger, 249-268.

SuÁrez PiÑeIro, A. (2002): “Galicia, ¿en la Ora maritima de R. F. Avieno?”, Cuadernos de Estudios Gallegos 49 n. ${ }^{\circ}$ 115, 9-26.

Susini, G. C. (1982): Epigrafia romana, Roma.

Conimbriga, 55 (2016) 193-219 
Tranoy, A. (1981): La Galice romaine. Recherches sur le nord-ouest de la péninsule ibérique dans l'Antiquité, Paris.

VASCONCElos, J. LeIte de (1927-1929): “Ara de Venus”, AP 28, 1928-1929, 142-144.

VÁzquez Saco, F. e VÁzquez SeiJas, M. (1954): Inscripciones romanas de Galicia II. Provincia de Lugo, Santiago de Compostela.

Villa VALDÉs, A. (2007): "Reseña del inventario arqueológico del concejo de Coaña y algunos apuntes relativos a su poblamiento prehistórico", en Excavaciones arqueológicas en Asturias 1999-2002, Oviedo, 413-418.

Villa Valdés, A. (2009a): Museo Castro de Chao Samartín, Grandas de Salime, Asturias. Catálogo, Oviedo.

VILLA VALDÉs, A. (2009b): “¿De aldea fortificada a caput civitatis? Tradición y ruptura en una comunidad castreña del siglo I d.C.: el poblado de Chao Samartín (Grandas de Salime, Asturias)", CuPAUAM 35, 7-26.

Villa VAldÉs, A. (2013): "El castro de Coaña. Un poblado fortificado en los albores de la historia de Asturias", en M. A. DE BLAs (Ed.), De neandertales a albiones: cuatro lugares esenciales en la Prehistoria de Asturias, Oviedo, 139-187.

Villa Valdés, A., Francisco Martín, J. e Alföldy, G., (2005): "Noticia del hallazgo de un epígrafe altoimperial en el lugar de Pelou, Grandas de Salime (Asturias)", AEspA 78, 271-274. 


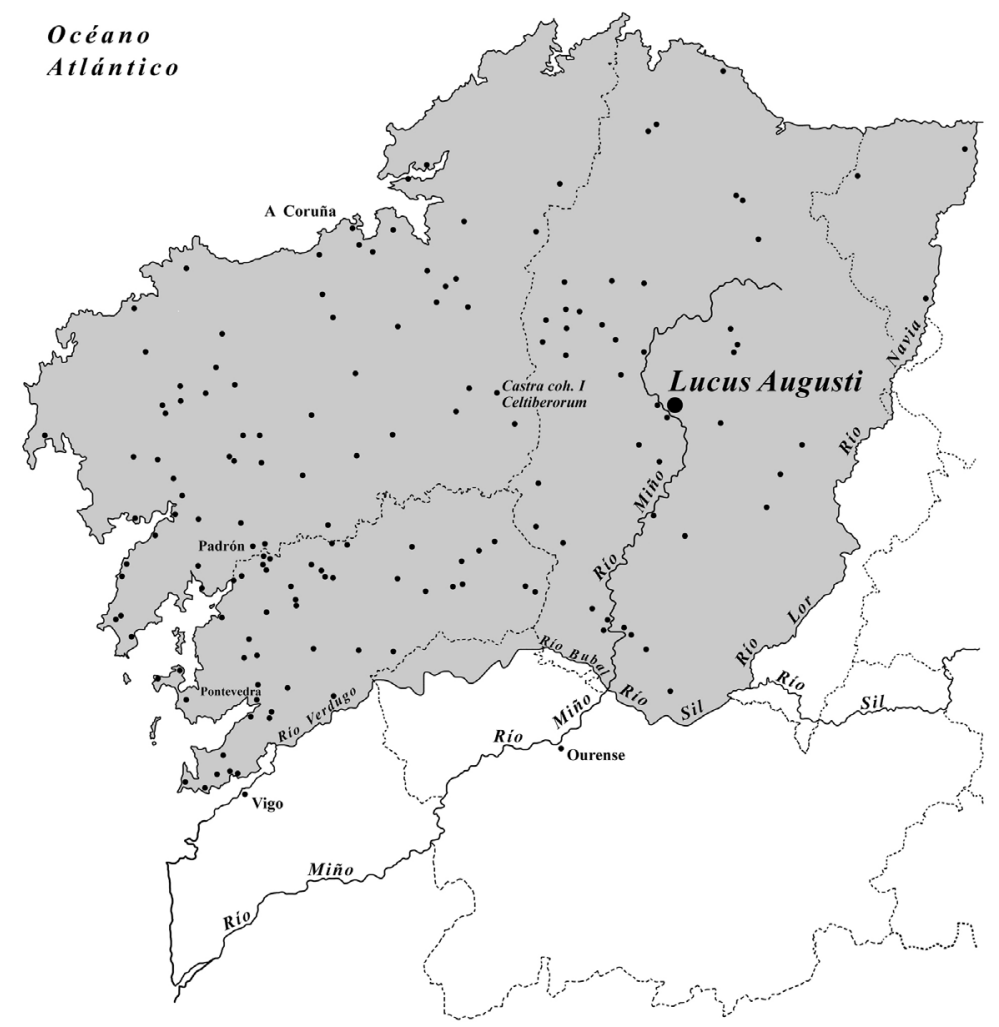

FIG. 1 - Limites probables del conventus Lucensis (zona sombreada en color gris), superpuestos sobre los límites administrativos actuales (líneas discontinuas).

Los puntos señalan los lugares en que se han producido hallazgos epigráficos romanos de cualquier tipo, incluyendo tanto miliarios como grafitos cerámicos (C J. M. Abascal). 


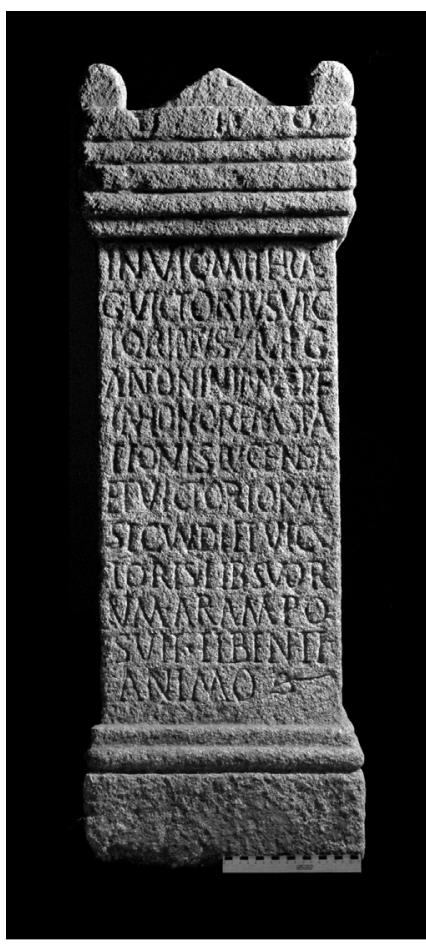

a

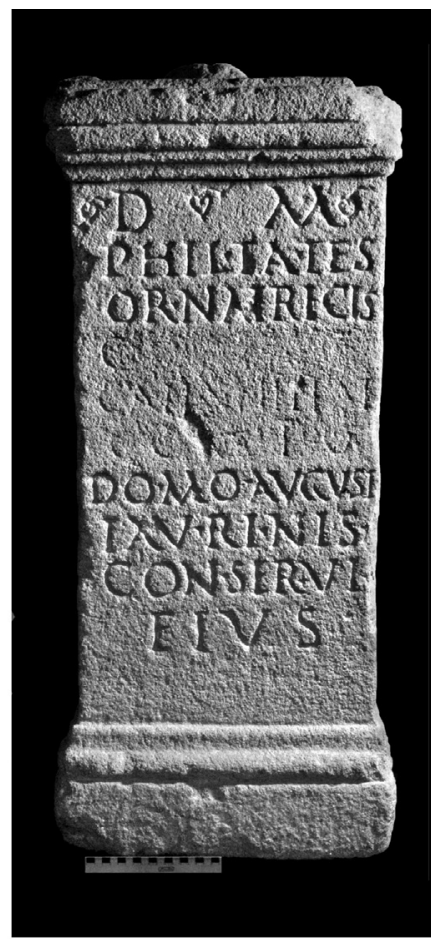

b

Fig. 2 - a) Altar de Lucus Augusti dedicado a Mithra;

b) altar funerario de Philtates (Fotos: J. M. Abascal). 


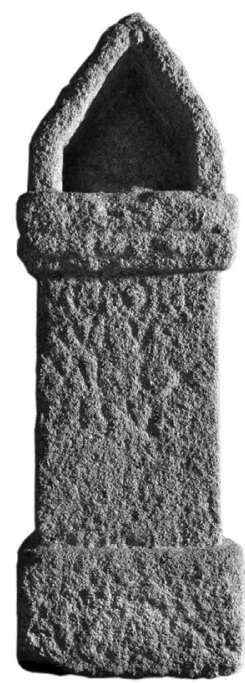

a

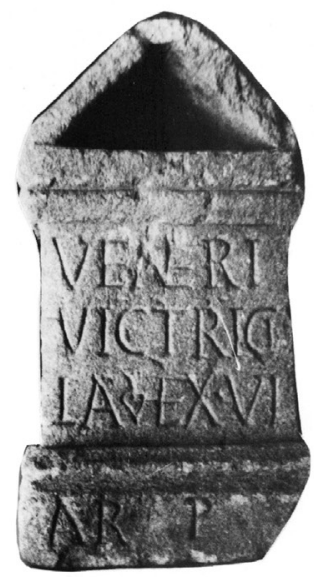

$\mathbf{b}$

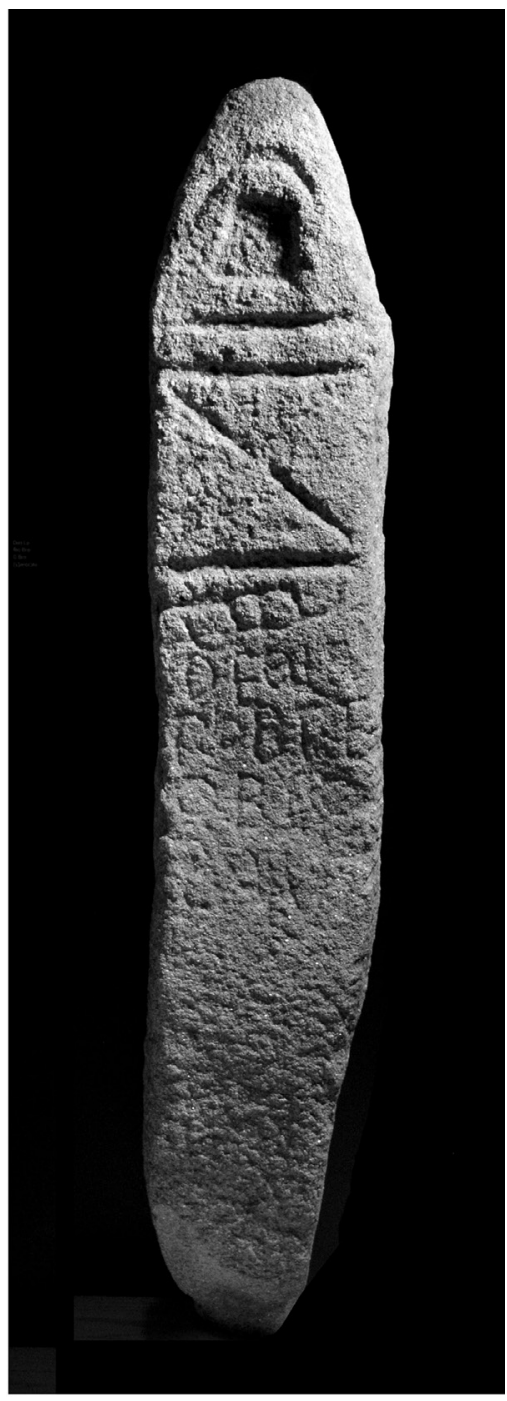

$\mathbf{c}$

FIG. 3 - a) Altar con la invocación Verore, de Lucus Augusti, conservado en el Museo de Lugo (Foto: J. M. Abascal); b) altar de Venus Victrix de Chaves (según Rodríguez Colmenero 1987); c) altar dedicado al Deus Lar Berobreus en el Facho de Donón (Hío, Pontevedra), conservado en el Museo de Pontevedra (Foto: J. M. Abascal).

La relación de tamaño entre unas y otras piezas respeta las dimensiones reales. 


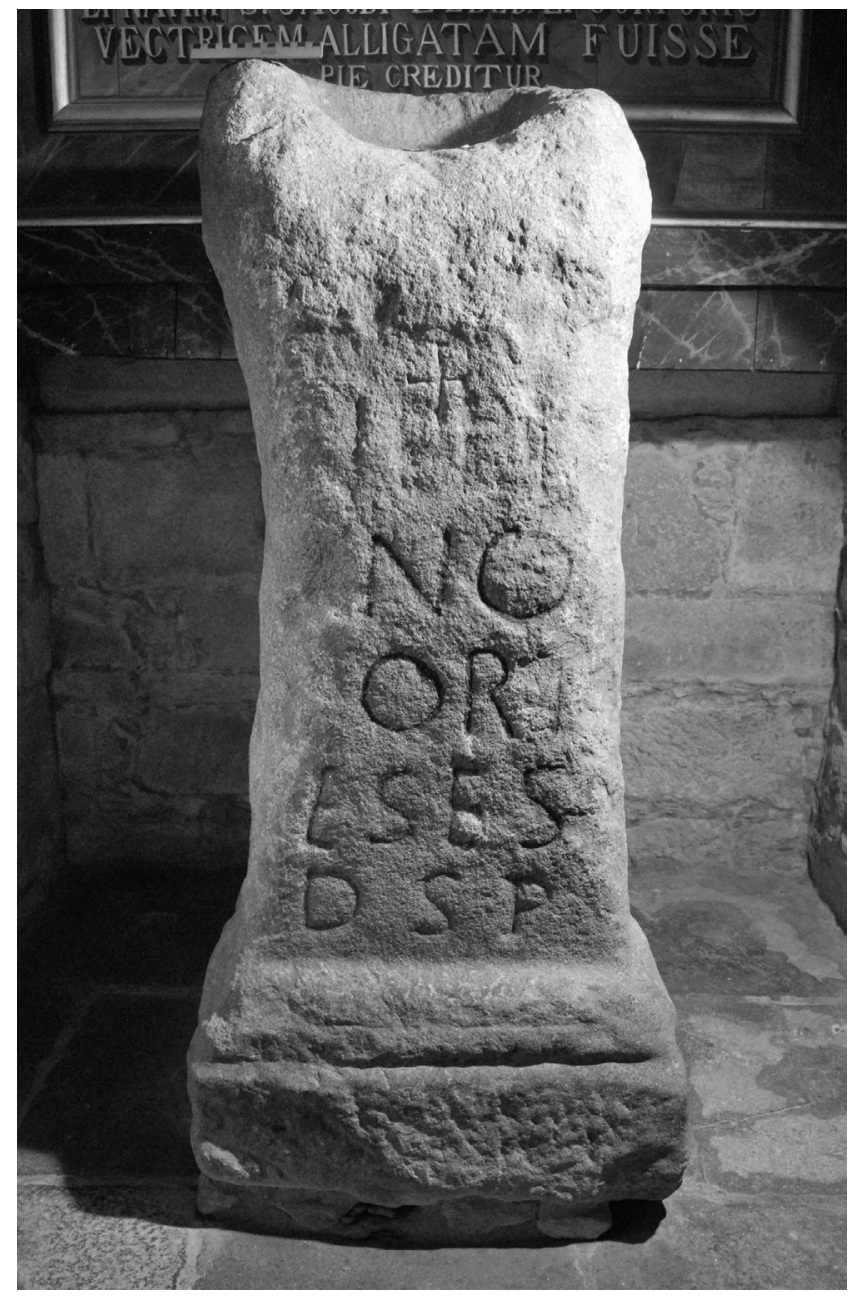

Fig. 4 - Altar dedicado a Neptuno en la iglesia de Santiago de Padrón (A Coruña).

En el ángulo superior izquierdo puede verse la escala que acompaña a la imagen. (Foto: J. M. Abascal). 

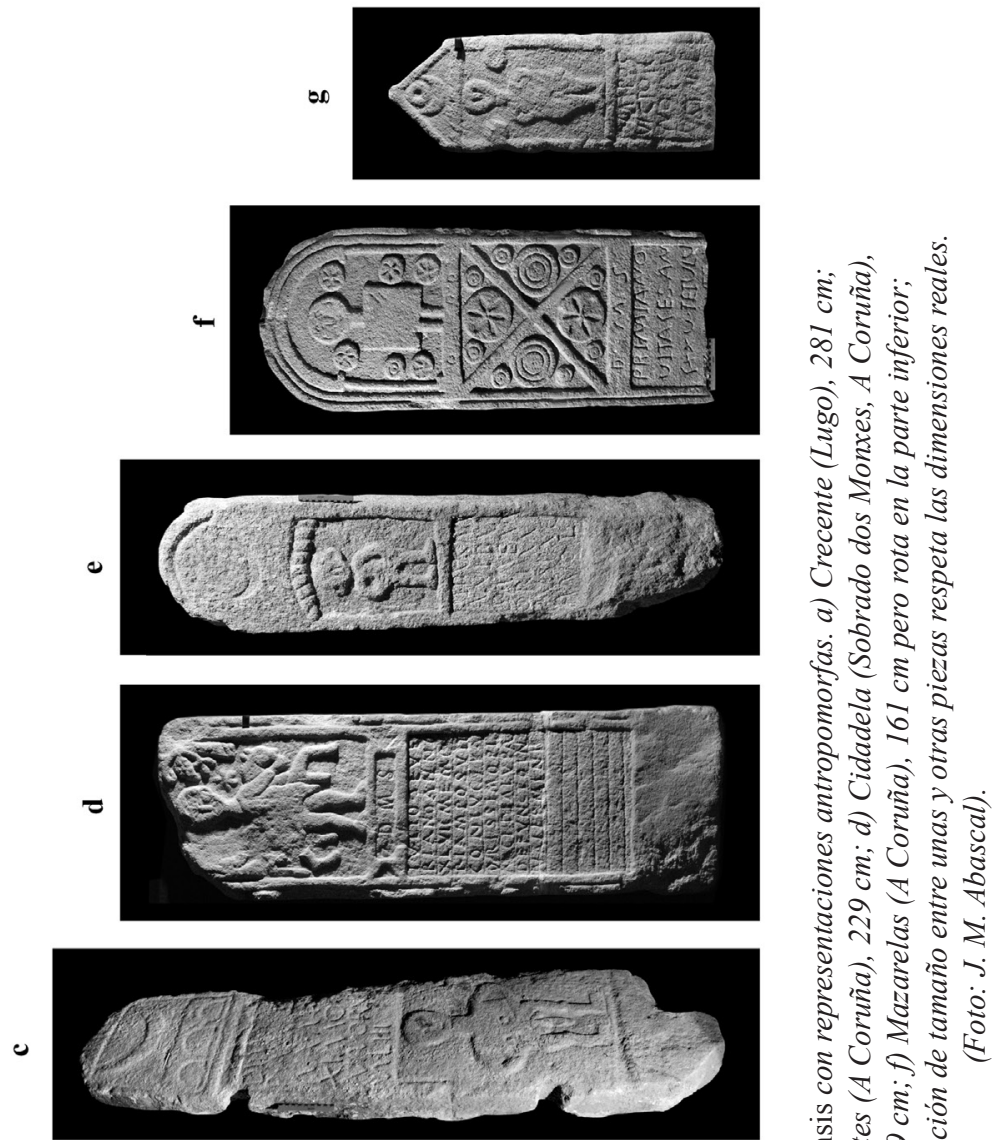

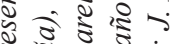

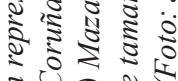

¿ $0<\frac{1}{2}$

य स

गี

วิ วิ

苟方

व 2 d

ป ป

० 20

ข

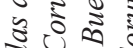

武苟

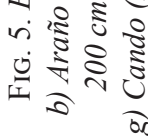

